\title{
APROXIMACIÓN A LA ESTRUCTURA SOCIOECONÓMICA DESDE UN ENFOQUE SOCIOCULTURAL: EL CONSUMO COMO VÍA A LA IDENTIDAD EN EL RÍO DE LA PLATA VIRREINAL*
}

APPROACH TO THE SOCIOECONOMIC STRUCTURE FROM A

SOCIOCULTURAL APPROACH: CONSUMPTION AS A WAY TO IDENTITY IN

THE RÍO DE LA PLATA VIRREINAL

Ana Clara Gastaldi

Estudiante de Historia

Universidad nacional de La Plata https://orcid.org/0000-0001-6850-1010

anaclarag17@gmail.com

Mariel Esjaita

Estudiante de Historia

Universidad Nacional de Tres de Febrero https://orcid.org/0000-0002-1373-3655 mariel.esjaita@gmail.com

\section{Resumen:}

Partiendo de la necesidad de aproximarse a las formas de la dominación y la estructuración social en el territorio rioplatense del Antiguo Régimen, entendemos que el consumo, en tanto fase final del proceso productivo, permite la expresión de formas de identificación y adscripción colectivas de los distintos sectores componentes del tejido social, en los que se conjugan factores de poder adquisitivo, así como expectativas sociales, prácticas, elecciones personales, e imaginarios comunes. En ese sentido, en este trabajo se buscará problematizar el estudio de la estratificación social en relación a los procesos de identificación, en particular para el espacio rioplatense virreinal, y empezar a establecer protocolos de trabajo para el estudio del consumo entre sectores populares y entre sectores de la élite, que permitan establecer patrones diferenciales entre los distintos sectores de la estructura social del Buenos Aires virreinal. Buscamos aproximarnos a este tópico desde una triple perspectiva, económica, social y cultural, trabajando desde una visión holística que permita dar cuenta de las particulares condiciones de la identificación en la sociedad porteña durante el Virreinato del Río 
de la Plata, como punto de partida para abordar el conjunto de los territorios implicados en el espacio económico rioplatense.

Palabras-clave: consumo, Río de la Plata, siglo XVIII

\begin{abstract}
:
Starting from the need to approach the forms of domination and social structuring in the Rioplatense territory of the Old Regime, we understand that consumption, as the final phase of the productive process, allows the expression of forms of collective identification and ascription of the different component sectors of the social fabric, in which factors of purchasing power are combined, as well as social expectations, practices, personal choices, and common imaginary. In this sense, this work will seek to problematize the study of social stratification in relation to identification processes, in particular for the Viceroyalty of Rio de la Plata, and begin to establish work protocols for the study of consumption between popular sectors and between sectors of the elite, that allow to establish differential patterns between the different sectors of the social structure of the viceregal Buenos Aires. We seek to approach this topic from a triple perspective, economic, social and cultural, working from a holistic vision that allows us to account for the particular conditions of identification in Buenos Aires society during the Viceroyalty of the Río de la Plata, as a starting point for address all the territories involved in the economic area of Rio de la Plata.
\end{abstract}

Keywords: consuption, Río de la Plata, XVIIIth century

\title{
Introducción
}

La preocupación por definir las formas en que se configura la estructura socioeconómica de la sociedad rioplatense del Antiguo Régimen nos ha conducido a preguntarnos por las prácticas de identificación colectiva de los distintos sectores que forman parte de dicha estructura.

Entre los desafíos que representa el estudio de las sociedades del pasado, poder inferir condiciones generales que nos den un cuadro del conjunto social más amplio está entre los más difíciles de saldar. Particularmente para sociedades de Antiguo Régimen, las fuentes más tradicionales no nos dejan ver a simple vista un cuadro más "completo" de las complejas articulaciones sociales que se desarrollaron.

No es la intención aquí desarrollar las múltiples dificultades que representa para el estudio histórico acceder a la multiplicidad de actores sociales que habitan cada 
periodo, especialmente a los denominados "sectores populares"; pero es este marco de complejidad de la estructura socioeconómica del Río de la Plata durante el Virreinato, el que nos ha llevado a plantearnos estrategias de abordaje del registro histórico que permitan aproximarnos al problema de la identificación.

Si bien a la luz de investigaciones recientes se puede vislumbrar el crecimiento económico de la región con minucioso detalle de mecanismos y rutas comerciales entre los siglos XVIII y XIX, también se puede inferir que gran parte de esa masa poblacional que se aventura al comercio trasatlántico y mercado interno, no necesariamente proviene de los sectores más altos de la sociedad rioplatense.

Siguiendo la línea de estos avances en la investigación económica proporcionados por nuestro equipo de trabajo y a la luz de nuevas fuentes documentales exploradas desde una mirada cultural y/o social, podemos aproximarnos al objeto de estudio desde una nueva óptica, alejándonos de a poco de los métodos tradicionales provenientes de la historia económica.

A partir de nuestra preocupación por la estructura y sus vinculaciones con los procesos de identificación, nos hemos propuesto avanzar en la construcción de hipótesis en torno al estudio de una de las prácticas identificatorias que podemos desentrañar en el registro documental, que es el consumo, para abordar dicha problemática en la sociedad del virreinato del Río de la Plata, dando cuenta de la diversidad estamental y cultural, así como también de la estratificación económica.

Para este fin, en nuestras investigaciones en curso centraremos el estudio en los bienes materiales, objetos de consumo y mercancías que circularon por Buenos Aires, indagando en el significado que los objetos adquieren a través de las personas, el valor cultural que representan y cómo influyen en su vida diaria, así como también en la interacción con otras regiones.

Para el caso hispanoamericano, muchas preguntas nacen de este planteo: ¿Pueden delimitarse grupos sociales a partir del consumo de bienes? ¿Qué lugar ocupa dentro del paradigma colonial el consumo de manufacturas europeas? Si la explicación tradicional respecto de la economía americana gira en torno a la colonialidad demostrada a través del comercio (en donde América entrega metal precioso a cambio de manufacturas europeas 
y bienes suntuosos para las élites)ํ: ¿qué sucede si se demuestra que el consumo es mucho mayor e incluso que los sectores subalternos adquieren estos bienes?, ¿Cambiaría esta circunstancia la naturaleza del vínculo colonial o su comprensión?

Si bien este capítulo no establece inequívocas respuestas a la mayoría de estos interrogantes, plantea al menos el punto de partida para un trabajo centrado en un análisis que intenta elevar la complejidad en comparación a los ya existentes, con la particularidad de una triple perspectiva histórica al entrelazar los niveles historiográficos de lo social, económico y cultural. La intención aquí es presentar el marco conceptual a partir del cual estamos construyendo un trabajo a dos manos en torno a la problemática del consumo, en estado incipiente a la fecha. Esta colaboración se nutre del trabajo individual de las dos autoras. Por un lado, la aproximación de Ana Clara Gastaldi sobre las pautas de consumo de la élite enfocadas particularmente en la vestimenta (entendida como "social skin”²), en función de entender los procesos de identificación social, y sus vinculaciones con la conformación de la esfera de poder. Por otra parte, el trabajo de Mariel Esjaita se propone aportar conocimientos en torno a los sectores populares de la sociedad virreinal, un estrato mencionado superficialmente en la historiografía, pero poco estudiado en profundidad debido la dificultad intrínseca al registro documental; dicho estudio se hará a través de una vía heterodoxa que es la reconstrucción de la vida material a través de fuentes testamentarias en una suerte de arqueología del archivo.

\section{Algunas consideraciones en torno al consumo}

El ámbito del consumo, definido como la fase final del proceso productivo, es un espacio de confluencia de elementos estructurales y superestructurales que nos permite visualizar en articulación procesos de construcción identitaria porque no implica solamente los aspectos vinculados a dinamización mercantil o a las formas que asume la demanda, sino que también echa luz sobre aspectos de apropiación social de los productos vinculados a la dinámica de diferenciación social ${ }^{3}$. En ese sentido, seguimos la idea de Enriqueta Quiroz

\footnotetext{
${ }^{1}$ La otra variable principal que sostiene la colonialidad americana es, como se sabe, la fiscalidad, que entiende las economías americanas en tanto que fuentes parasitarias de renta en favor de la metrópolis y atribuye a la innegable (y toda vez que se pueda creciente) exacción fiscal atributos diferentes a la ejercida por el mismo poder monárquico en sus dominios europeos.

${ }^{2}$ Definición de: Terence S. Turner, "Social skin", en J. Cherfas y R. Lewin (Eds.), Not work alone: A crosscultural view of activities apparently superfluous to survival, Londres, Maurice Temple Smith, 1980, pp. 112-143, pp. 112-143.

${ }^{3}$ Néstor García Canclini, Ideología, cultura y poder. Buenos Aires, Oficina de Publicaciones del CBC/Universidad de Buenos Aires, 1995, http://www.ram-wan.net/restrepo/poder/canclini.pdf (consulta 10/02/2019).
} 
al considerar al estudio histórico del consumo en su integralidad: "no podemos quedarnos con la idea de que éste es la última y menos importante fase del proceso económico, sino que insisto en la propuesta de entenderlo como un proceso integral, que logra articular y dar sentido a todas las etapas"4.

Dentro de la historiografía americanista, el consumo ha sido estudiado desde una perspectiva ligada a la historia económica, descuidando las relaciones que se pueden tejer con la historia social, hasta tiempos relativamente recientes, en que se ha puesto énfasis en esta relación dialéctica que se expresa en el consumo en obras como la de Quiroz. Sin embargo, es un campo que contiene cierta potencialidad explicativa aun no exhaustivamente explotada a cabalidad.

Para el periodo de dominación hispánica en el continente americano, la mayor parte de los estudios de consumo se han enfocado en cuestiones dietarias y nutricionales, con la idea de establecer parámetros de nivel de vida. Cabe destacar fundamentalmente los múltiples trabajos sobrela instalación delos cultivos dela denominada "tríada mediterránea" (trigo, oliva y vid), siendo explicado este proceso por "cuestiones de paladar", lo cual es una tradición explicativa muy extendida, evidente en lo que recoge Arnold Bauer ${ }^{5}$. Es nuestra opinión que otros elementos pudieron intervenir en dicha instalación, que implicó profundos cambios en las producciones autóctonas que ya estaban desarrollándose por siglos, y eran igualmente nutritivas y productivas, preexistentes en el territorio americano. Debieron intervenir factores vinculados a la satisfacción de consumos alimentarios que en la península fueron demarcadores de la élite (pan blanco, vino, aceite de oliva), y que los españoles en América, no provenientes de una extracción de abolengo, sino de diversas categorías sociales más o menos populares, vieron en su nueva condición en América la posibilidad de acceder a esa dieta. A partir de esta noción, y pensando en otros sectores del consumo que se enfocan más en el individuo dentro de un colectivo, entendemos que puede inferirse un proceso homologable al dietario, en el cual los consumos de los actores se guíen por la satisfacción de aspiraciones personales en el marco de una suerte de "supervivencia social" en un contexto de heterogénea movilidad social.

Hacemos hincapié en este punto de vista "cultural" sobre el consumo porque pretendemos que, a partir de un anclaje desde la historia económica, podamos empezar

\footnotetext{
${ }^{4}$ Enriqueta Quiroz, El consumo como problema histórico. Propuestas y debates entre Europa e Hispanoamérica, México, Instituto Mora, 2006, p. 81.

${ }^{5}$ Arnold J. Bauer, Somos lo que compramos: historia de la cultura material en América Latina, México, Taurus, 2002.
} 
a pensar nuevas explicaciones sobre los “modos de vida" de la sociedad rioplatense, trascendiendo las miradas exclusivamente económicas. Esta visión antropológica sobre el consumo, siguiendo el planteo de Sidney $\mathrm{Mintz}^{6}$, permite articular el análisis económico puro con los usos y costumbres de los grupos sociales del pasado, dando un anclaje material concreto a las hipótesis que construyamos desde lo cultural.

\section{El marco historiográfico para el Antiguo Régimen americano. El problema de los Modos de Producción}

Consideramos que el marco de análisis sobre el que partimos para la construcción de una explicación sobre la estructura socioeconómica rioplatense se sustenta en debates ya añejos de la historiografía local que se han constituido en paradigma vigente sobre el Antiguo Régimen americano, puntualmente las nociones sobre los Modos de Producción en América Latina tal como fueran expresadas en la obra homónima publicada en los Cuadernos de Pasado y Presente en 1973. Los trabajos compilados allí representan una importante síntesis sobre un debate amplio y profundo que se extendió por varios años, en torno a establecer una definición sobre el funcionamiento de la allí llamada "relación colonial". El eje de la discusión se centra en refutar explicaciones circulacionistas partiendo de una posición clave que es la de entender al foco de la dominación como "externo" al territorio: “... si hay algo que da sentido a todo el sistema en nuestros espacios coloniales, ese elemento es la relación colonial y no tal o cual modo de producción nativo.”7

Esta idea que expulsa la dominación principal hacia la metrópoli no nos estaría diciendo mucho sobre las estructuraciones internas locales americanas. Si bien el modelo que nace de este debate para dar cuenta de las formas que asume la economía en nuestra región de interés, que es el esbozado por Carlos Sempat Assadourian ${ }^{8}$, representa una sistematización mucho más elaborada desde una perspectiva materialista innovadora con respecto a aplicaciones marxistas más vulgares previas en la academia, también contiene limitaciones. El sistema de la economía colonial, y la noción de espacio económico que aplica para dar cuenta de las relaciones entre regiones americanas que propone articular, sobre una base teórica marxista sólida, conceptualizaciones provenientes de vertientes del desarrollismo, así como su interés en dar cuenta de las condiciones propias, particulares de América, entendiendo que los modelos construidos en Europa

\footnotetext{
6 Sidney W. Mintz, Dulzura y poder. El lugar del azúcar en la historia moderna, México, Ed. Siglo XXI, 1996.

7 Juan Carlos Garavaglia, "Introducción”, en Modos de producción en América Latina, Cuadernos de Pasado y Presente, 40, México, 1973, p. 14.

${ }^{8}$ Carlos Sempat Assadourian, El sistema de la economía colonial. El mercado interior, regiones y espacio económico, México, Editorial Nueva Imagen, 1983.
} 
no tienen necesariamente que contener a los procesos que se dieron en nuestro continente. En ese sentido, es interesante el marco metodológico que plantea, apuntando a tomar las preguntas del Marx más clásico, antes que buscar aplicar las respuestas. No deja de resultar paradigmático que su propia propuesta, elaborada en un marco de intensos debates, se haya constituido finalmente en un modelo para la aplicación de una receta ya aprobada, en una “explicación hegemónica”.

Es digno de evidenciar que el concepto de "colonia" que subyace al modelo sigue conteniendo los rasgos clásicos del concepto de colonialismo que han sido acuñados para la expansión imperial europea (británica principalmente) del siglo XIX, a saber: 1) mercado cautivo, y 2) extracción parasitaria de renta. Sería conveniente tomar esta conceptualización con cuidado cuando se la aplica para el periodo que va entre los siglos XVI y XVIII en el continente americano, porque existe el riesgo de caer en anacronismos y extrapolaciones erróneas.

Es a partir de estas preocupaciones en torno al "modelo hegemónico" que nos permitimos salir del marco pautado y pensar explicaciones locales a menor escala que luego puedan o no confluir con perspectivas de mayor alcance, es decir, no buscamos confirmar ni refutar el modelo, si no explicar lo que las fuentes nos permitan ver.

\section{Diferentes sectores estudiados de la sociedad rioplatense:}

\section{Las élites locales}

Por las formas en la que se ha ido construyendo el registro documental en el Antiguo Régimen, problemática a la que ya hemos hecho mención anteriormente, la bibliografía en torno al modo de vida de los actores de las élites es mucho más abundante. Sin embargo, los enfoques que se han privilegiado, que son muy relevantes para tomar como punto de partida para los estudios de consumo en el sector, se vinculan a las problemáticas del parentesco como forma básica de estructuración social y conformación de grupos.

Una obra que abre la puerta al conocimiento de un sector destacable de la élite es "Los mercaderes del Buenos Aires virreinal: familia y comercio" de Susan Socolow ${ }^{9}$, en la que encontramos una serie de síntesis clave sobre la formación de este colectivo social que conformaban los comerciantes en el Río de la Plata.

9 Edición consultada: Susan Socolow, Los mercaderes del Buenos Aires virreinal: familia y comercio, Buenos Aires, Ediciones de la Flor, 1991. 
Como se ha mencionado anteriormente, la historiografía reconoce en el comercio, fundamentalmente el transatlántico, la actividad central y dinamizadora de la región rioplatense. Partiendo de este conocimiento, es ineludible concluir que los actores que lleven a cabo dicha actividad tendrán niveles de preeminencia social, y es así como lo han abordado diversos autores. Socolow describe en el mencionado trabajo las características de tal preeminencia, brindando elementos interesantes sobre los cuales hacer foco para aproximarse a una mejor comprensión de la elite rioplatense en su conjunto.

La autora nos introduce a la élite comercial haciendo foco en varios aspectos, entre los cuales se destacan los estudios del parentesco y la familia, y del estilo de vida y la socialización. Los estudios de familia constituyen un porcentaje más que importante entre el total de los trabajos sobre los sectores de élite de Hispanoamérica, para todo el período desde la conquista a las independencias, hasta llegar a la historia reciente. Cabe destacar que las interrelaciones que se ha tejido en la historiografía (y en el conjunto de las ciencias sociales) en función del rol del parentesco en el establecimiento de alianzas políticas y económicas, no es un rasgo excluyente de los sectores de poder, ni propio del Antiguo Régimen, sino que es parte de las prácticas mejor documentadas sobre el parentesco en la larga duración y en todos los estratos sociales y las diversidades culturales. De todas maneras, aquí queremos hacer referencia a la visión de Socolow sobre este tema, quien hace hincapié en la vinculación entre las relaciones comerciales y las estrategias matrimoniales, en continuidad con otras estudios anteriores y posteriores que relacionan estos aspectos, así como también las conductas migratorias del sector comerciante: "El matrimonio y el parentesco ritual vinculaban entre ellos a los comerciantes de Buenos Aires y formaban poderosos clanes mercantiles. Las mujeres de los comerciantes, sus esposas e hijas, servían para reclutar nuevos comerciantes en los clanes, perpetuando de esta manera el grupo de comerciantes y forjando nuevas alianzas." ${ }^{10}$

Sobre el problema del parentesco en el Antiguo Régimen del virreinato del Río de la Plata, otro conjunto de trabajos ${ }^{11}$, más recientes, que merecen destacarse tienen que ver con los estudios sobre élites locales del interior del virreinato, centrados en sus

${ }^{10}$ S. Socolow, Los mercaderes, p. 65.

${ }^{11}$ Por ejemplo: Roxana Boixadós, "Familia, herencia e identidad. Las estrategias de reproducción de la elite en La Rioja colonial, siglo XVII y principios del XVIII", en Revista de Demografía Histórica, No 19, 2, 2001, pp. 147-182; Judith Farberman, "Los que se van y los que se quedan: familia y migraciones en Santiago del Estero a fines del período colonial", en Quinto Sol, $\mathrm{N}^{\circ}$ 1, 1997, pp. 7-40; Josefina Mallo, "Privilegios entre hermanos y situación social: los hermanos Pessoa”, en Beatriz I. Moreyra \& Silvia C. Mallo (Comps.), Pensar y construir los grupos sociales. Actores, prácticas y representaciones, Córdoba y Buenos Aires, siglos XVI-XX, Córdoba, Centro de Estudios Históricos "Prof. Carlos S. A. Segreti" / La Plata, Centro de Estudios de América Latina Colonial, 2009, pp. 241-251. 
estrategias de parentesco y patrimoniales. Presentan una relevancia en tanto estudios de caso, pero también en tanto modelos metodológicos de trabajo documental. Por ejemplo, las investigaciones de Roxana Boixadós en torno a la élite riojana entre los siglos XVII y XVIII dejan planteadas interesantes interacciones entre la esfera de lo público y lo privado, lo patrimonial y lo estamental, así como el rol de la familia extensa, el parentesco ficticio y los hijos naturales y/o mestizos:

... enfocando el problema desde la perspectiva de una familia de élite vimos que ésta integraba de manera desigual a miembros ilegítimos, naturales y mestizos, los que en conjunto parecen haber conformado pequeños subgrupos articulados a través de vínculos de parentesco, dependencia, obligaciones, favores y reciprocidades de toda índole. De aquí se desprende que pertenencia y desigualdad pueden ser dos dimensiones clave para comprender la dinámica de los procesos de formación de la identidad de estas personas y sus familias -y de las mismas en tanto grupo o sector diferenciado dentro de la sociedad. ${ }^{12}$

Particularmente, la relación que se teje entre el patrimonio y el honor del grupo familiar, entendido este como colectivo de intereses más que como conjunto de relaciones consanguíneas, es una propuesta más que interesante para enfocar la problemática de las vinculaciones entre la esfera de lo económico y lo social en una sociedad de Antiguo Régimen.

El segundo de los aspectos destacables del enfoque sobre las élites de Socolow mencionado más arriba es tal vez el que mejor nos presenta aspectos de la interacción, cooptación y reconocimiento internos del sector comerciante como colectivo social de élite, y posiblemente sea el aspecto que aún los estudios no han complejizado y profundizado a cabalidad. Socolow brinda un cuadro sobre la sociabilidad de la élite comerciante en el que interactúan lo ritual, lo estamental y lo material en formas diversas. Asimismo, el estilo de vida de élite que se reconstruye está cargado de elementos que trascienden al sector mercantil, y es posible extrapolar que las necesidades sociales de estos son también las de otros sectores de poder, así como las que conforman las expectativas a lograr por sectores medios en ascenso ${ }^{13}$. Por otra parte, es interesante mencionar que es en este plano, y en relación con lo que tiene que ver con los consumos "suntuarios", donde podemos empezar

\footnotetext{
${ }^{12}$ Roxana Boixadós, "No ha tenido hijo que más se le parezca así en la cara como en su buen proceder. Una aproximación al problema del mestizaje y la bastardía en la Rioja colonial”, en Memoria Americana, N 13, 2005 , pp. 83-115. ${ }_{13}$ Para mayor profundización sobre estos "sectores medios" remitimos al exhaustivo trabajo de María Emilia Sandrín sobre las mujeres productoras de bizcocho para el comercio trasatlántico. María Emilia Sandrín, "La demanda de bienes y servicios para la Corona y la navegación ultramarina en el complejo portuario rioplatense y la dinamización de la economía regional. 1680-1810”, Tesis de Doctorado inédita, Universidad Nacional de La Plata, 2016.
} 
a apreciar verdaderas mixturas entre estrategias modernas y de Antiguo Régimen, que combinan la acumulación y el despilfarro en una sola práctica: "La decisión de invertir los beneficios en bienes suntuarios para consumo personal, en lugar de volver a invertirlos en negocios, tierras urbanas o barcos, la tomaban hombres más interesados en hacer dinero que en gastarlo. Sin embargo, los comerciantes se sentían atraídos por la ropa elegante, los muebles y las joyas, indicación de que sus valores eran los mismos que los de toda la gente prominente del mundo hispánico"14

Estas nociones que deja planteadas en su estudio Socolow nos brindan un excelente punto de partida para reconstruir las disputas intra élite, que pudieran haber tenido implicancias en los proyectos de emancipación que cuajan ya en el siglo XIX. Y también nos dejan intuiciones muy acertadas en relación con la posibilidad de la movilidad social dentro de una sociedad nominalmente estamental. Si acaso hay algún aspecto a cuestionar del trabajo de Socolow, sea tal vez la falta de una especificación en torno a los criterios de selección en la muestra que toma de individuos y familias, a los que describe como "los más exitosos" en términos adquisitivos en el Buenos Aires virreinal, pero no están del todo claros cuales son los parámetros del éxito, ni cuáles son los límites del poder adquisitivo que permiten el ingreso al grupo, ni cuanta distancia habría con respecto a otros sectores del comercio menos acaudalados, ni cuáles son los patrimonios de estas familias que son denominadas "de la élite", o como este patrimonio los hace acreedores de otras formas de poder. Aunque cabe destacar que se encuentran en su muestra la mayoría de los "grandes apellidos" del período, es decir, los personajes que se destacan son todos ampliamente conocidos para la historiografía, con lo cual podemos inferir que la aproximación de Socolow se adscribe dentro de la lógica de las "élites de archivo"15 a las que refiere Fernando Jumar cuando habla sobre aquellos individuos particulares cuyo registro documental ha sido más prolífico, y por tanto, de mucho más fácil acceso para los investigadores.

Por otra parte, los estudios de redes sociales aplicados a los sectores de las élites virreinales, fundamentalmente centrados en un enfoque vinculado a sus funciones políticas y económicas, aportan nociones y conceptos relacionados con las formas de cooptación ${ }^{16}$. El eje de los debates va a estar marcado por la dicotomía establecida entre

\footnotetext{
${ }^{14} \mathrm{~S}$. Socolow, Los mercaderes, p. 105.

${ }^{15}$ Fernando Jumar, "Comerciantes en Río de la Plata pre-virreinal. El caso de Domingo de Basavilbaso", en Anuario del Instituto de Historia Argentina, Universidad Nacional de La Plata, Nº 11, 2011, pp. 207-241.

${ }^{16}$ Una síntesis de los debates puede encontrarse en la compilación de trabajos presentada "Análisis de los grupos sociales: balance historiográfico y debate crítico”, Dossier, Anuario IEHS, No 15, 2000, pp. 23-171.
} 
los estudios desde la prosopografía y desde las redes sociales. Tomando en consideración que ambos enfoques presentan ventajas y limitaciones, se puede reconocer un consenso en la academia en torno a la necesidad de hacer confluir ambas miradas para explicar el fenómeno de la dominación en Hispanoamérica. Pueden considerarse que los estudios sobre redes de parentesco que en los últimos años se han producido con mucho éxito para espacios particulares dentro del imperio español, dan cuenta de esa necesidad de síntesis, y son muy elocuentes en términos de sus aportes a la comprensión del fenómeno global a partir de la articulación entre sus partes.

En la bibliografía al respecto, es destacable el lugar que se le da al mestizaje entre las élites, sobre todo en un marco de contradicciones entre modernidad y larga duración, a la vez que las ubica en marco general de la sociedad americana, en la que los valores culturales atraviesan todos los estratos:

... una lectura diferencial de las fuentes nos lleva de hecho hacia una realidad plural y sumamente evolutiva: la de un modelo cultural que se difunde en el conjunto de la sociedad indiana, de la transmisión de un sistema de valores que encontramos hasta en los estratos extremos de la sociedad colonial (...) el afán de nobleza se consigue donde uno menos se lo espera a lo largo y ancho de la sociedad indiana. ${ }^{17}$

Esta idea es valiosa para la comprensión de las expectativas sociales no solo de la élite, sino de todos los sectores, y nos permite poner en evidencia que hay valores que atraviesan las condiciones estamentales, étnicas y de clase y se constituyen es aspiraciones del conjunto de la "sociedad indiana". Esto será de central relevancia en las explicaciones que se puedan construir en torno a la movilidad social en el Antiguo Régimen americano.

Por otra parte, puede considerarse de relevancia la noción que plantea Tamar Herzog en torno al rol de la "negociación" en los procesos de identificación y pertenencia intra élite. La autora parte de la problematización en torno a las categorías institucionales que nacen en el contexto peninsular, particularmente la de "vecino", y como estas encarnan en prácticas en América que muchas veces subvierten el sentido original del término, y se convierten en nuevos conceptos que dan acceso a formas de socialización novedosas:

"tanto "vecino", como "militar", "indio" y "español”, eran categorías de orden tanto social como legal, y que su contenido y significado no eran evidentes, ni tenía

${ }^{17}$ Frédérique Langue, "Las élites en América española. De la historia de las prácticas a la práctica de la historia", en Anuario IEHS, N 15, 2000, pp. 101-116, p. 101. 
sentido -dentro de la lógica del sistema jurídico del Antiguo Régimen buscar su definición teórica y general. Su aplicación a ciertas personas respondía a una visión de la sociedad, una visión que incluía tales consideraciones como su organización interna y su división en grupos, y que no dejaba de considerar tampoco las relaciones personales que unían a los miembros de la corporación. ${ }^{18}$

Esta noción es relevante para poner énfasis en la posibilidad de agencia que los actores concretos pudieron desarrollar en sus prácticas cotidianas, sobre todo en relación con posibles estrategias de ascenso social o ventaja económica.

Por último, es interesante hacer hincapié en la noción de originalidad americana en la construcción de sus instituciones desde cero, sin un sustrato feudal preexistente en el territorio, pero con un importante aporte desde la multiculturalidad que se evidencia en los españoles del común devenidos colonizadores, que nos lleva a pensar en que la autoridad oscila entre el foco único de la monarquía y la multiplicidad localizada de los poderosos de cada región: "la ausencia aquí, desde los orígenes, de sistemas o cuerpos intermediarios (régimen señorial, cortes u otros) ha reforzado la autoridad del rey (y de su alter ego). El clientelismo, personal y vertical se expresa aquí en toda su pureza."19 Ante esta noción, a la que se hace necesario matizar en función de la lógica mestiza americana que venimos mencionando, se presenta la necesidad de hacer entrar en conexión dos fenómenos que son sincrónicos a la vez que contradictorios en la América de Antiguo Régimen: la originalidad local y la búsqueda de reproducir patrones peninsulares. En esta tensión van a configurar su poder las élites americanas.

Hasta el momento, tenemos una caracterización de los sectores que denominamos élites que da un marco interesante para el planteo de preguntas que profundicen la problemática más general de la estructura rioplatense virreinal. Particularmente, con las explicaciones que se han venido produciendo en relación con las prácticas de interacción entre familias de comerciantes, podemos ver indicios de acciones concretas que vinculan el poder económico y el poder político, que nos pueden permitir vislumbrar nuevas explicaciones para la interrelación entre ambas esferas que nos lleve a complejizar la mirada sobre este momento histórico de transición entre formas tradicionales y modernas de agencia social.

\footnotetext{
${ }_{18}$ Tamar Herzog, "La vecindad: entre condición formal y negociación continua. Reflexiones en torno a las categorías sociales y las redes personales", en Anuario IEHS, $\mathrm{N}^{\circ}$ 15, 2000, pp. 123-131, p. 127.

19 Thomas Calvo, "Comentario a las ponencias de M. Bertrand y J-P Zúñiga”, en Anuario IEHS, N 15, 2000, pp. 81-85, pp. 82.
} 
En ese sentido, nos planteamos la posibilidad de pensar hipótesis en torno a mecanismos híbridos, "mestizos”, entrelas prácticas estamentales más propias del Antiguo Régimen, y una incipiente configuración de clases en el sentido moderno del término, que puedan expresarse en formas de movilidad social más dinámicas. Las características que asuma el consumo en los diferentes actores sociales colectivos pueden ser un buen indicador de prácticas concretas de identificación (y cooptación) sectorial, y por ende de acceso a esferas de interacción en lo político y lo económico.

Y aunque la situación del Río de la Plata puede seguir considerándose marginal, y los niveles de opulencia que se manejan no llegan a compararse a los que podemos encontrar en el Perú o Nueva España, aun así, sus pautas de socialización siguen estando contenidas dentro de lo que Juan Carlos Garavaglia llama "barroco hispánico terminal”, sobre todo entre los sectores de la élite. Esta desigualdad en la riqueza no hace mella en el abolengo de los actores, en el estatus del que se consideran y son considerados merecedores.

Cabe destacar que, siguiendo esta idea de barroco terminal, el periodo que nos interesa puede ser definido como un momento transicional, o de formas intermedias, entre un Antiguo Régimen en decadencia y una modernidad que no termina de instalarse. En ese "momento intermedio" se cruzan fenómenos de la larga duración con estrategias innovadoras en una síntesis de conductas novedosas que deben articularse en los patrones de lo tradicional. El ceremonial propio del Antiguo Régimen mantiene vigencia a la vez que se va transformando para dar cuenta de las propias transformaciones que va sufriendo la sociedad.

Entre las múltiples transiciones que se producen al unísono, sea tal vez la más relevante de mención la que se da en el cruce entre una lógica estamental y una de clases para la distinción social. Si bien en el plano oficial, las condiciones estamentales son las que determinan las posibilidades de acción en la esfera institucional del gobierno, así como también son condicionantes de las capacidades de interacción e integración social de los individuos, en la esfera de los usos y las costumbres, existen indicios que nos llevan a pensar que las normas al respecto no eran inflexibles, y por el contrario eran susceptibles de ser ignoradas en beneficio de otros intereses, sobre todo económicos.

${ }^{20}$ Juan Carlos Garavaglia, "El teatro del poder: ceremonias, tensiones y conflictos en el estado colonial”, en Boletín del Instituto de Historia Argentina y Americana “Dr. Emilio Ravignani”, Tercera Serie, N 14, 1996, pp. 7-30. 
La sociedad rioplatense, de forma semejante a muchas otras sociedades de Antiguo Régimen, constituyó una representación de sí misma, y los actores en ese escenario del mundo contaban con el conocimiento para actuar su papel de la forma más verosímil posible: la pertenencia al grupo es por apariencia, que es lo que determinaría, en último término, la aceptación del resto de los miembros.

Si bien a una escala completamente diferente, el planteo de Norbert Elías, pensado para la sociedad cortesana, sobre el uso de la etiqueta y ceremonial como herramientas de estructuración social, puede aplicarse al objeto de nuestro estudio. ${ }^{21}$ Continuando la idea de "barroco terminal" de Garavaglia para caracterizar este contexto histórico, entendemos que en la sociedad rioplatense "el hábito hace al monje", y que "ser" y "parecer" son condiciones inescindibles en la construcción del estatus, que es siempre colectivo.

\section{Sectores populares o Subalternos}

A diferencia del primer grupo, este último es más difícil de delimitar por varios motivos: escasa referencia en la bibliografía, poca trascendencia en su accionar, limitada o nula participación en la vida política de las ciudades, ausencia de testimonios escritos y más aún, testamentos a su nombre.

La historiografía reciente alumbra desde hace unos años a este conglomerado de personas ubicado en la base de la pirámide social, siempre haciendo hincapié en la problemática de definición y nomenclatura de estos sectores. Se los llamó "pobres", "la gente de abajo", "trabajadores independientes", "los que mantenían relaciones de subalternidad con las élites o clases dominantes", "esclavos", "indios", "negros", "no blancos", etc. Entre las definiciones de índole académico podemos utilizar el término que Di Meglio instaura en su tesis doctoral: "Bajo Pueblo" ${ }^{22}$ bajo la justificación que es un término que ya utilizaba la elite rioplatense y es una construcción recurrente en otras ubicaciones geográficas.

Por lo demás, en este caso particular consideramos que la delimitación debe darse en pos de su ocupación o nivel de ingresos económicos y no en relación con su composición fenotípica, raza o procedencia.

Es entonces como nuestro estudio desemboca en la demografía, es decir, el estudio

${ }^{21}$ Norbert Elias, La sociedad cortesana, México, Fondo de Cultura Económica, 1996.

${ }^{22}$ Gabriel Di Meglio, iViva el bajo pueblo! La plebe urbana de Buenos Aires y la política entre la revolución de mayo y el rosismo, Buenos Aires, Prometeo, 2006. 
de los censos y series de evolución de población urbana (para este caso en particular, son de fácil acceso los padrones de ciudad y campaña de Buenos Aires en 1744, 1778, 1810/15); donde más allá de la falencia de datos muy detallados en torno a condiciones o montos, pueden vislumbrarse cierta pluralidad y diversidad de ocupaciones en la campaña. Una buena muestra de ello es el cuadro elaborado por Martín Cuesta sobre la estructura económica de la ciudad de Buenos Aires y su campaña en 1744, 1778 y 1810 que permite conocer la distribución proporcional de los habitantes en función de sus actividades económicas. ${ }^{23}$

Calculado sobre la base del total de población con actividad declarada más los esclavos, donde la magnitud de los sectores secundario y terciario en los tres censos es un indicador de que esta población es diferente a otras sociedades preindustriales. De ello, el autor desprende que "la producción primaria no era predominante, por lo que sugiere una ciudad comercial continuada con un hinterland que la abastece y que brinda al mismo tiempo un producto de exportación. También indica una economía ligada al tráfico comercial y, después de 1776 , cabeza de un virreinato”. ${ }^{24}$

Si tomamos el trabajo de María Emilia Sandrín en torno a las bizcocheras, podemos identificar este esquema en donde este grupo que ella denomina con prudencia "sectores medios" de la población, vive de proveer comestibles (bizcocho) a embarcaciones de la navegación ultramarina y que presentan una relativa prosperidad.

La producción de insumos vitales para el funcionamiento del complejo portuario rioplatense y el comercio minorista entonces estará también en manos de actores que no son reconocidos como (y en consecuencia no serían) parte de la élite del virreinato, y, sin embargo, son influyentes en la configuración de redes sociales en el territorio rioplatense.

Otro ejemplo de este grupo son los pulperos, señalados por Julián Carrera ${ }^{25}$, quien retomando los trabajos de Carlos $\mathrm{Mayo}^{26}$, además de medir el grado de mercantilización de la campaña, en su trabajo observa que se puede afirmar que la pulpería sería la puerta

\footnotetext{
${ }^{23}$ Eduardo Martín Cuesta, Precios, población, impuestos y producción: la economía de Buenos Aires en el siglo XVIII, Buenos Aires, Temas Grupo Editorial, 2009, p. 41.

${ }^{24}$ E. M. Cuesta, Precios, población, p. 42.

${ }_{25}$ Julián Carrera, Algo más que mercachifles: pulperos y pulperías en la campaña bonaerense: 1770-1820, Rosario, Prohistoria Ediciones, 2011.

${ }^{26}$ Carlos A. Mayo, Pulperos y pulperías de Buenos Aires: 1740-1830, Mar del Plata, Universidad Nacional de Mar del Plata/Facultad de Humanidades, 1997.
} 
de acceso a otros negocios de la campaña bonaerense como la compra de ganado o de tierras. Eso deja entrever el replanteo en la relación entre comercio y producción.

En este borrosamente delimitado grupo subalterno enfocaremos también el estudio de la cultura material y hábitos de consumo, describiendo y categorizando a estos individuos con criterios que emerjan de las fuentes.

\section{Cuestiones metodológicas}

En función del estado de la cuestión anteriormente planteado, nuestras investigaciones en curso están empezando a abordar la esfera del consumo en el Río de la Plata virreinal, buscando sumar la visión sociocultural a los trabajos que desde el colectivo de investigadores en el que estamos insertas se han desarrollado sobre la esfera económica del espacio y período tomados. El estado incipiente de nuestros trabajos particulares no nos permite más que plantear hipótesis educadas en función de lo que la perspectiva que intentamos desarrollar nos permite observar en la bibliografía, y en un primer y muy somero acercamiento a las fuentes documentales.

La aproximación a través del consumo que intentamos abordar tiene por objeto dar cuenta de la condición transicional de la sociedad rioplatense, atrapada entre lo moderno y lo premoderno, en la que pareciera configurarse una estructuración social en la que encontramos aspectos estamentales y de clase en interacción.

Detodas maneras, y por esta curiosa combinatoria, las formas de adscripción social a los diferentes estratos existentes no estaban tan claramente ligadas a la ubicación objetiva de los actores en el sistema productivo, sino que se concatenan múltiples factores en ese proceso, dentro de los cuales el poder expresar, a través del consumo de determinados productos, el modo de vida propiamente español, habría sido, en relación, el que más peso específico aportó para ubicar a los individuos en un escalón de la pirámide o en otro.

Teniendo en cuenta que existe en el espacio rioplatense una relativa prosperidad económica que alcanza hasta a los sectores populares, es esperable encontrar en esos sectores prácticas de consumo que buscan emular el estilo de élite, considerando que los "márgenes de libertad" relativos que manejaban, principalmente en relación a la entrada y salida del mercado del trabajo, en conjunto con ingresos que permitían satisfacer de 
forma adecuada las necesidades más básicas, de alimento y vivienda ${ }^{27}$, aspectos que facilitan la decisión de destinar parte del ingreso a bienes que podemos considerar de lujo. Esta dinámica social daría lugar también a una estructura social mucho más rica y compleja, en la que múltiples sectores intermedios pudieran florecer, y acceder a diferentes posibilidades de interacción social ${ }^{28}$.

En esta instancia es que, en nuestras investigaciones en curso, nos proponemos abordar desde dos puntos de vista complementarios el problema del consumo, cada uno de ellos tomando como eje un sector diferenciado de la escala social conocida para el periodo.

Por una parte, una visión "desde arriba”, que estará centrada en el consumo de las élites: el acceso a los llamados "efectos de Castilla" debió ser marcador de la condición social, de las posibilidades económicas, pero también socioculturales de acción en el ámbito público. Este aspecto del consumo como constructor de identidad lo vemos exacerbado en especial en algunos tipos de mercancía que, indistintamente de su condición de uso, adquieren valor en vinculación con lo que representan en el escenario de la vida social. El caso de la vestimenta es paradigmático para esta situación: constituye un elemento central en la imagen que los individuos construyen para sus relaciones sociales, en términos de identificación y reconocimiento. La circulación de textiles en el Río de la Plata ya cuenta con aproximaciones preliminares en estudio ${ }^{29}$, que estarían indicando que los textiles de importación se ubican entre los bienes más importantes, en cantidad, dentro de los artículos europeos que ingresan a la región. En ese sentido, la propuesta de profundización para esta perspectiva consiste en el establecimiento de un protocolo para el análisis de los textiles que vea dichos productos desde el plano de la circulación, y del consumo concreto. Para lo primero, el trabajo sobre las guías de aduana se hace central. Para lo segundo, una fuente como las testamentarias sería apropiada para un relevamiento preliminar que permita establecer protocolos susceptibles de ser contrastados.

El segundo foco de interés estará puesto en los denominados "sectores populares”, y considerando las salvedades que se han expresado más arriba con

\footnotetext{
${ }^{27}$ Fernando Jumar y María Emilia Sandrín, “¿A panza llena corazón contento? La economía rioplatense, el estado llano y general del pueblo y la adhesión a la revolución”, en Jornadas internacionales: Independencia, Historia y memoria. Hacia una reflexión de los procesos revolucionarios en Iberoamérica, San Miguel de Tucumán, Argentina, 2009.

${ }^{28} \mathrm{M}^{\mathrm{a}}$. E. Sandrín, "La demanda de bienes y servicios".

${ }^{29}$ Fernando Jumar, "La circulación de textiles desde Buenos Aires entre 1779 y 1783”, en Guillermina del Valle Pavón y Antonio Ibarra (Coords.), Redes, corporaciones y mercados hispanoamericanos en la economía global, siglos XVIIXIX, México, Instituto de Investigaciones Dr. José María Luis Mora/CONACyT, 2017, pp. 229-276.
} 
respecto a las limitaciones del registro, para el estudio del consumo en estos sectores se propone analizar las condiciones materiales de vida y hábitos de consumo según las pertenencias halladas en los inventarios Post Mortem (Ab Intestato) y respaldadas por inventarios patrimoniales y testamentos de fines del siglo XVIII y principios del siglo XIX.

En este punto, contamos con un antecedente historiográfico en torno al consumo de bienes onerosos o exóticos que no corresponden a necesidades básicas de la población, destacando así el trabajo de Mariano Bonialian ${ }^{30}$; quien afirma que la vía de comercio oriental constituyó un engranaje necesario para la economía regional y detalla minuciosamente los productos chinos que ingresaron al virreinato; particularmente los textiles y la seda, los cuales destaca el autor, son algo más accesibles que sus equivalentes españoles o europeos. Afirma entonces que mientras las élites criollas e hispanas habrían intentado distinguirse utilizando textiles más caros traídos desde Europa, la seda china sería dedicada a una cultura de consumo cotidiano. No encontramos otros testimonios que acompañen lo que asevera Bonialian, pero consideramos que sus ideas merecen ser revisadas al calor de las fuentes, ya que podrían contener potencialidades aún no exploradas en el trabajo documental exhaustivo.

La fuente privilegiada que utilizaremos para el trabajo propuesto, son aquellas pertenencias halladas en los inventarios Post Mortem (Ab Intestato) y respaldadas por inventarios patrimoniales y testamentos de fines del siglo XVIII y principios del siglo XIX.

La importancia de estas fuentes se remonta a la tradición jurídica impuesta desde la conquista, que regía tanto para Buenos Aires como para toda América hispana, estos bienes inventariados y tasados que pertenecían al difunto al momento del deceso formaban parte de los procesos sucesorios de la época. La legislación Castellana establecía desde las Siete Partidas la instancia de inventario en los procesos testados o Ab Intestatos, al parecer en un primer momento con el objetivo de determinar el pago de las deudas del fallecido, y luego como garantía de justicia en el proceso de transmisión de bienes a los herederos ${ }^{31}$.

En el caso particular de Buenos Aires, el archivo perteneciente al Juzgado de Bienes

${ }^{30}$ Mariano Ardash Bonialian, "China en la América colonial: bienes, mercados, comercio y cultura del consumo desde México hasta Buenos Aires” Buenos Aires, Biblios/Instituto Mora, 2014.

${ }^{31}$ Un trabajo que también aborda la temática testamentaria es el de Natalia Stalla, "De testamentos, ab-Intestatos e inventarios: Régimen sucesorio en el Río de la Plata durante la época colonial”, en Proyecto Historia de los mercados en el Río de la Plata, 1760-1860, Montevideo, Universidad de la República/Ministerio de Educación y Cultura del Uruguay, 2009. 
de Difuntos y Pertenencias Extrañas se encuentra hoy conservado en el Archivo General de la Nación.

La jurisdicción de este organismo comprendía las sucesiones de difuntos que fallecían sin testamento o cuyos herederos residían en España. También administraba y, eventualmente vendía, los bienes que no habían sido reclamados. Dado que estos bienes podían pasar a formar parte del Patrimonio Real, era de gran importancia ocuparse de ellos hasta que se definiera su destino definitivo, de manera de evitar su deterioro o usurpación.

Todo se desarrollaba en base a un procedimiento donde, fallecida la persona, primero se aseguraban los bienes cerrando las habitaciones. Luego se hacía el inventario. Una vez asegurados y contados, los bienes iban a un depósito donde quedaban a cargo del Teniente de Oficiales Reales llamado para esta ocasión “el depositario”. En ese momento se nombraba un Defensor de Bienes, en general algún vecino que conociera al difunto, que ayudaba a reconocer las pertenencias, así como también a los legítimos herederos. Concluidos los pasos anteriores, seguía la parte económica del proceso. Se designaba al tasador, quien procedía de acuerdo con los precios de plaza y al estado de bienes. Luego tenía lugar la almoneda, es decir, la venta pública. Con lo recaudado, en primer lugar, se pagaban el funeral y las deudas del difunto, cuyo monto no era raro que superara la cantidad obtenida en el remate. El resto de lo percibido se remitía a la Audiencia, para que lo guardara en la Caja de Difuntos donde permanecía hasta ser enviado a España, junto con todos los documentos del caso, a fin de hacer un nuevo intento por ubicar a los herederos.

Para procesar estas fuentes, en primera instancia se esbozará un inventario con el detalle de determinados bienes onerosos embargados y tasados para que, a partir de las similitudes halladas, se puedan establecer patrones de adquisición de objetos extra-americanos. Del mismo modo se tomarán en cuenta aquellos objetos que dada su peculiaridad, permanezcan fuera de todo patrón establecido. Para acotar la cantidad de fuentes y ante la poca certeza de los límites y autoridades vigentes (y la continua variación de las mismas) este trabajo tomará como espacio geográfico al entorno urbano que rodeaba al cabildo de Buenos Aires y el espacio rural más próximo con el que interactúan los habitantes, como primera etapa de aproximación, y como testeo de la propuesta metodológica, con la intención de ampliar la región con los avances posteriores. 
Dado que el consumo de bienes onerosos, atraviesa transversalmente a todos los habitantes del Buenos Aires virreinal, para un primer análisis se tomará un sector medio de la población existente sin diferenciar los matices de castas que allí se encuentren, ya que la mirada a este nivel será en pos de sus consumos y adquisiciones, apartando a los extremos de mayores ingresos (grandes comerciantes, funcionarios de la corona, o poseedores de extensos patrimonios) y a los de menores ingresos (esclavos e indigentes). Se hará foco entonces, en aquellas personas asalariadas o pequeños comerciantes con ingresos medios. El recorte se hará en base a la lista de ocupaciones brindada por Lyman Johnson $^{32}$, complementada con los datos acerca de pulperos proporcionados por Julián Carrera ${ }^{33}$.

En un segundo plano se relacionará la información obtenida con algunos conceptos provenientes de la historia cultural como ser: "sistema de objetos", "signo", "valor de uso" y "valor de cambio" desprendidos del marco teórico aportado por Jean Baudrillard ${ }^{34}$ y Roger Chartier ${ }^{35}$. En esa instancia el objetivo será indagar sobre la imagen de las cosas o al significado de lo que las ideas representaban en aquella sociedad en particular.

\section{Consideraciones finales}

Para finalizar, este trabajo plantea el punto de partida de un análisis más profundo en torno a la cultura material de la sociedad virreinal, elevando la complejidad en comparación a los ya existentes y con la particularidad de poseer una triple perspectiva histórica al entrelazar los niveles historiográficos de lo social, lo económico y lo cultural, y cuyo objetivo final es obtener un cuadro más completo, acabado y profundo de la vida cotidiana en el Virreinato del Río de la Plata, sus actores, sus costumbres y, en virtud de todo ello, aproximarse a sus ideas.

Es importante hacer hincapié en que el énfasis puesto en la cultura material es una definición teórica en función de sostener un enfoque materialista sobre la problemática de la construcción de identidades colectivas, lo cual no descarta, sino que enriquece otras formas de análisis sobre fuentes cualitativas.

Nuestras hipótesis de trabajo en este momento apuntan a reconocer niveles de

\footnotetext{
${ }^{32}$ Lyman Johnson, "Salarios, precios y costo de vida en el Buenos Aires colonial tardío”, en Boletín del Instituto de Historia Argentina y Americana Dr. Emilio Ravignani, Tercera Serie, Nº 2, 1990, pp. 133-157.

33 J. Carrera, Algo más que mercachifles.

34 Jean Baudrillard, El sistema de los objetos, México, Siglo XXI, 1981.

${ }^{35}$ Roger Chartier, El mundo como representación: estudios sobre historia cultural, Buenos Aires, Gedisa, 2002.
} 
dinamismo social propios de un momento de transición entre lo estamental y lo moderno, en el que la agencia personal de los actores sociales pudo haber pesado mucho más que su adscripción étnica. En ese contexto, los procesos de identificación colectiva vinculados al consumo podrían ser determinantes para el acceso y la pertenencia a diferentes sectores sociales, y esto puede tener consecuencias en el plano de lo político.

La relevancia de esta investigación oscila entre varias aristas: por un lado, aporta elementos que ayudarán a discernir si el consumo de bienes onerosos existente en la población de medianos y escasos ingresos responde a una significación cultural específica para ese sector. En segundo lugar, colabora con la sustentación de la hipótesis de nuestro grupo de trabajo en torno a la existencia de la relativa prosperidad en el Río de la Plata durante el Antiguo Régimen, y su consiguiente correlación con mayores niveles de movilidad social. Y en tercer lugar, puede también respaldar la teoría de Brown donde el desarrollo de la actividad económica en el Río de la Plata impulsa el crecimiento de un mercado interno dinamizador de la economía y la sociedad.

Por último, dicha relevancia en la construcción de una explicación sobre las formas que asume la estructura socioeconómica rioplatense radica en la complejización que aporta a la mirada sobre los procesos de dominación locales, sobre las prácticas concretas de estratificación social que son el sustrato sobre el cual se construyen los sistemas de poder. Entendemos que la sociedad que estamos mirando no es menos compleja que la sociedad que nacerá de su seno con el proceso independentista, muy por el contrario pensamos que hay por ver tantas continuidades como rupturas, y que los procesos de larga duración que se expresan en pautas como la del consumo, ancladas en representaciones colectivas del "deber ser", son fundamentales para la configuración de cualquier explicación sobre las transformaciones sociales de este momento de "pasaje" entre el Antiguo Régimen y la modernidad.

Es nuestro objetivo el visualizar niveles de agencia entre los actores sociales locales del Río de la Plata. Estamos convencidas que una mejor comprensión de las prácticas concretas conducirá a mejores explicaciones sobre la dominación, la resistencia, y la transformación social. Todos estos elementos nos permitirán la elaboración colectiva de modelos más ricos y más complejos para dar cuenta de la vida rioplatense. 
Ana Clara Gastaldi - Mariel Esjaita

\section{Bibliografía}

Assadourian, Carlos Sempat, El sistema de la economía colonial. El mercado interior, regiones y espacio económico, México, Editorial Nueva Imagen, México, 1983.

Baudrillard, Jean, El sistema de los objetos, México, Siglo XXI, 1981.

Bauer, Arnold J., Somos lo que compramos: historia de la cultura material en América Latina, México, Taurus, 2002.

Boixadós, Roxana, "Familia, herencia e identidad. Las estrategias de reproducción de la elite en La Rioja colonial, siglo XVII y principios del XVIII”, en Revista de Demografía Histórica, $\mathrm{N}^{\mathrm{o}}$ 19, 2, 2001, pp. 147-182.

Boixadós, Roxana, "No ha tenido hijo que más se le parezca así en la cara como en su buen proceder. Una aproximación al problema del mestizaje y la bastardía en la Rioja colonial", en Memoria Americana, N 13, 2005, pp. 83-115.

Bonialian, Mariano Ardash, "China en la América colonial: bienes, mercados, comercio y cultura del consumo desde México hasta Buenos Aires”. Buenos Aires, Biblios/ Instituto Mora, 2014.

Calvo, Thomas, "Comentario a las ponencias de M. Bertrand y J-P Zúñiga”, en Anuario IEHS, $\mathrm{N}^{\circ} 15,2000$, pp. 81-85.

Carrera, Julián, Algo más que mercachifles: pulperos y pulperías en la campaña bonaerense: 1770-1820, Rosario, Prohistoria Ediciones, 2011.

Chartier, Roger, El mundo como representación: estudios sobre historia cultural, Buenos Aires, Gedisa, 2002.

Cuesta, Eduardo Martín, Precios, población, impuestos y producción: la economía de Buenos Aires en el siglo XVIII, Buenos Aires, Temas Grupo Editorial, 2009. 
Di Meglio, Gabriel, iViva el bajo pueblo! La plebe urbana de Buenos Aires y la política entre la revolución de mayo y el rosismo, Buenos Aires, Prometeo, 2006.

Elías, Norbert, La sociedad cortesana, México, Fondo de Cultura Económica, 1996.

Farberman, Judith, "Los que se van y los que se quedan: familia y migraciones en Santiago del Estero a fines del período colonial”, en Quinto Sol, $N^{\circ}$ 1, 1997, pp. 7-40.

Garavaglia, Juan Carlos, "El teatro del poder: ceremonias, tensiones y conflictos en el estado colonial", en Boletín del Instituto de Historia Argentina y Americana "Dr. Emilio Ravignani”, Tercera Serie, 14, 1996, pp. 7-30.

Garavaglia, Juan Carlos, "Introducción”, en Modos de producción en América Latina, Cuadernos de Pasado y Presente, $\mathrm{N}^{\circ}$ 40, México, 1973, pp. 7-16.

García Canclini, Néstor, Ideología, cultura y poder. Buenos Aires: Oficina de Publicaciones del CBC/Universidad de Buenos Aires, 1995, disponible en http://www.ram-wan. net/restrepo/poder/canclini.pdf (consulta 10/02/2019).

Herzog, Tamar, "La vecindad: entre condición formal y negociación continua. Reflexiones en torno a las categorías sociales y las redes personales", en Anuario IEHS, $\mathrm{N}^{\circ} 15$, 2000, pp. 123-131.

Johnson, Lyman, "Salarios, precios y costo de vida en el Buenos Aires colonial tardío", en Boletín del Instituto de Historia Argentina y Americana "Dr. Emilio Ravignani”, Tercera Serie, 2, 1990, pp. 133-157.

Jumar, Fernando, "Comerciantes en Río de la Plata pre-virreinal. El caso de Domingo de Basavilbaso", en Anuario del Instituto de Historia Argentina, Universidad Nacional de La Plata, $\mathrm{N}^{\circ}$ 11, 2011, pp. 207-241.

Jumar, Fernando, "La circulación de textiles desde Buenos Aires entre 1779 y 1783", en Valle Pavón, Guillermina del \& Ibarra, Antonio (Coords.), Redes, corporaciones 
y mercados hispanoamericanos en la economía global, siglos XVII-XIX, México, Instituto de Investigaciones Dr. José María Luis Mora/CONACyT, 2017, pp. 229276.

Jumar, Fernando \& Sandrín, María Emilia, “¿A panza llena corazón contento? La economía rioplatense, el estado llano y general del pueblo y la adhesión a la revolución", en Jornadas internacionales: Independencia, Historia y memoria. Hacia una reflexión de los procesos revolucionarios en Iberoamérica, San Miguel de Tucumán, Argentina, 2009.

Langue, Frédérique, "Las élites en América española. De la historia de las prácticas a la práctica de la historia”, en Anuario IEHS, $\mathrm{N}^{\circ}$ 15, 2000, pp. 101-116.

Mallo, Josefina, "Privilegios entre hermanos y situación social: los hermanos Pessoa", en Moreyra, Beatriz I. \& Mallo, Silvia C. (Comps.), Pensar y construir los grupos sociales. Actores, prácticas y representaciones, Córdoba y Buenos Aires, siglos XVI-XX, Córdoba, Centro de Estudios Históricos "Prof. Carlos S. A. Segreti” / La Plata, Centro de Estudios de América Latina Colonial, 2009, pp. 241-251.

Mayo, Carlos A., Pulperos y pulperías de Buenos Aires: 1740-1830, Mar del Plata, Universidad Nacional de Mar del Plata/Facultad de Humanidades, 1997.

Mintz, Sidney W., Dulzura y poder. El lugar del azúcar en la historia moderna, México, Ed. Siglo XXI, México, 1996.

Quiroz, Enriqueta, El consumo como problema histórico. Propuestas y debates entre Europa e Hispanoamérica, México, Instituto Mora, 2006.

Sandrín, María Emilia, "La demanda de bienes y servicios para la Corona y la navegación ultramarina en el complejo portuario rioplatense y la dinamización de la economía regional. 1680-1810", Tesis de Doctorado inédita, Universidad Nacional de La Plata, 2016. 
Socolow, Susan, Los mercaderes del Buenos Aires virreinal: familia y comercio, Buenos Aires, Ediciones de la Flor, 1991.

Stalla, Natalia, "De testamentos, ab-Intestatos e inventarios: Régimen sucesorio en el Río de la Plata durante la época colonia", en Proyecto "Historia de los mercados en el Río de la Plata. 1760-1860, Montevideo, Universidad de la República/Ministerio de Educación y Cultura del Uruguay, 2009.

Turner, Terence S., "Social skin”, en Cherfas, J. \& Lewin, R. (Eds.), Not work alone: A crosscultural view of activities apparently superfluous to survival, Londres, Maurice Temple Smith, 1980, pp.112-143.

VV. AA, “Análisis de los grupos sociales: balance historiográfico y debate crítico”, Dossier, Anuario IEHS, $\mathrm{N}^{\circ}$ 15, 2000, pp. 23-171. 